\title{
Mechanical Properties of Pineapple Leaf Powder Filled High Density Polyethylene
}

\author{
I.O. Eze ${ }^{1, a^{*}}$, I.O. $\operatorname{Ig}^{1, \mathrm{~b}}$, O. Ogbobe ${ }^{1, \mathrm{c}}$, E.E. Anyanwu ${ }^{2, \mathrm{~d}}$, I. Nwachukwu ${ }^{3, \mathrm{e}}$ \\ ${ }^{1}$ Department of Polymer and Textile Engineering, Federal University of Technology, Owerri, \\ P. M. B. 1526, Owerri, Nigeria \\ ${ }^{2}$ Department of Mechanical Engineering, Federal University of Technology, Owerri, \\ P. M. B. 1526, Owerri, Nigeria \\ ${ }^{3}$ Department of Microbiology, Federal University of Technology, Owerri, \\ P. M. B. 1526, Owerri, Nigeria \\ ainnocento4u@yahoo.com, bik3gh@gmail.com, 'ogbobeokoro1@yahoo.com, \\ 'eemmanuelanyanwu@yahoo.com, ${ }^{\mathrm{e} i k e n n a t e x @ y a h o o . c o m ~}$
}

\begin{abstract}
Keywords: Pineapple leaf powder, High density polyethylene, Composites, Mechanical properties, Adhesion, Injection moulding technique.
\end{abstract}

\begin{abstract}
The effects of pineapple leaf powder (PALP) on the mechanical properties of high density polyethylene (HDPE) composites were studied. HDPE and PALP composites were prepared by injection moulding technique. The filler (PALP) contents investigated were 2, 4, 6, 8, and $10 \mathrm{wt} \%$ for each formulation. The result of the mechanical tests carried out on the HDPE/PALP composites showed that the tensile strength, tensile modulus, flexural strength, abrasion resistance, and hardness of the composites increased as the filler content increases for all the filler contents investigated while the elongation at break (EB) for PALP/HDPE composites was found to decrease as the filler content increases for all the filler contents investigated. The tensile strength of PALP/HDPE composites was increased by $6.49 \%$ at $2 \mathrm{wt} \%$ filler content, and $30.39 \%$ at $10 \mathrm{wt} \%$ filler content. It was also observed, from the results, that the elongation at break of PALP/HDPE composites was decreased by $2.40 \%$ at $2 \mathrm{wt} \%$ filler content, and $10.24 \%$ at $10 \mathrm{wt} \%$ filler content. The present study has highlighted the utility of pineapple leaf powder (PALP) as reinforcing filler in HDPE compounding. Pineapple leaf, which is an agricultural waste has been shown to have potential as a cheap, more readily available and more environmentally friendly filler.
\end{abstract}

\section{Introduction}

Nowadays, the growing environmental awareness throughout the world has triggered a paradigm shift towards the design and development of environmental-friendly materials. Consequently, natural fibres are attracting more interest as reinforcements for both thermoplastic and thermosetting polymer composites [1,2]. Natural fibres (as fillers) from renewable resources offers the potential to act as biodegradable reinforcing materials that are alternative to the use of glass or carbon fibre as fillers in the polymer industry. The use of natural fibres has the following advantages: low cost, lightweight, renewable in character, biodegradability, high specific strength and modulus, availability in a variety of forms, absence of associated health hazards, easy fibre surface modification, and relative non-abrasiveness [3]. Biocomposites that are derived from natural fibres/fillers and traditional thermoplastics or thermosets have the capacity to maintain a balance between economy and environment. This makes it possible for these materials to be considered for applications in the fields of automotives, aerospace, defence, marine, sporting goods, building, furniture and packaging industries.

A number of studies have been reported in the literature on the use of natural fibres to reinforce polymers. [9] investigated the effects of fibre contents on the tensile properties of micro winceyette fibre reinforced corn starch composites and found that the tensile strength of the composites was approximately trebled when the fibre content increased from 0 to $20 \% \mathrm{wt}$. However, the elongation at break decreased with increase in fibre content. 
Similarly, Lee et al. [10] studied kenaf and jute fibre reinforced polypropylene, and found that the tensile strength and Young's modulus increased with increase in fibre content, reached a maximum, and thereafter, decreased with further increase in fibre content.

Rozman et al. [11] studied the use of coconut fibre as reinforcement in polypropylene hybrid composites, and reported that the incorporation of the fibre led to reduction in the tensile, flexural, and impact strengths of the composites. This observation was attributed to incompatibility between the fibre and polypropylene matrix, as well as on the irregularity in the fibre size. However, increasing the fibre content was found to lead to improvement in the tensile strength, and flexural modulus of the composites.

Khoathane et al. [12] who investigated the effects of bleached hemp fibre contents on the tensile strength of the fibre reinforced 1-pentene/polypropylene copolymer composites found that the tensile strength increased from $20 \mathrm{MPa}$ to $30 \mathrm{MPa}$ when the fibre content was $5 \%$. However, the tensile strength dropped to $23 \mathrm{MPa}$ when the fibre content was $20 \%$, and later increased again, the value of which was the same as that of $30 \%$ fibre content.

Bujang et al. [13] studied the dynamic characterization of coir fibre reinforced polymer composites and found that the tensile modulus changed with increasing fibre content. The tensile strength of the coconut fibre reinforced composites tended to decrease with increases in fibre content, an indication of an ineffective stress transfer between the fibre and matrix.

The aim of this study is to investigate the use of pineapple leaf powder (PALP) as filler in compounding HDPE.

\section{Materials and Methods}

\subsection{Materials}

High density polyethylene (HDPE) and pineapple leaf powder were used in this study. The high density polyethylene (HDPE) used in this study was obtained from Ceeplast Industries, Aba, Abia state, Nigeria. It has a density of $0.97 \mathrm{~g} / \mathrm{cm}^{3}$, and melt flow index of $9.0 \mathrm{~g} / 10 \mathrm{~min}$. at $170{ }^{0} \mathrm{C}$. Pineapple leaf powder (PALP) was used as a filler in this study. The pineapple leaves from where the powder was prepared were collected from a pineapple orchard near Umuagwo Polytechnic, Owerri, Imo State, Nigeria. The processing equipments used includes Mesh sieve $(0.3 \mathrm{~mm})$, cutlass, injection moulding machine (Negri Bossi, Italy), instron machine (Instron 1td., United Kingdom), electronic weighing balance (Contech, India), shredding machine, permanent marker (Ink), grinding machine, personal protective equipment (PPE).

\subsection{Pineapple Leaf Powder preparation}

Pineapple leaves collected from Umuagwo, Imo State, Nigeria were cut into smaller sizes and sun-dried for fourteen days. The dried leaves were later oven-dried for $24 \mathrm{hrs}$ at $80^{\circ} \mathrm{C}$ prior to grinding. A manual grinder was used to grind the chopped dry pineapple leaves into powder. The pineapple leaf powder (PALP) obtained was sieved with a sieve grid of $0.3 \mathrm{~mm}(75 \mu \mathrm{m})$.

\subsection{Preparation of High Density Polyethylene Composites}

High Density Polyethylene composites of the pineapple leaf powder (PALP) were prepared by thoroughly mixing $200 \mathrm{~g}, 198 \mathrm{~g}, 196 \mathrm{~g}, 194 \mathrm{~g}, 192 \mathrm{~g}$ and $190 \mathrm{~g}$ of high density polyethylene with $0,2,4,6,8$ and $10 \mathrm{wt} \%$ filler contents respectively. The formulated blend compositions were each processed at the same temperature $\left(165^{\circ} \mathrm{C}\right)$ using an injection moulding machine.

\subsection{Measurement of Mechanical Properties}

Tensile properties of the composites were determined by using an Instron Testing Machine (Lloyds, capacity 1-20 kN) according to standard method (ASTM D638). The tensile properties of HDPE composites that were determined are: (i) tensile strength, (ii) elongation at break, and (iii) tensile modulus. Other properties of the composites that were determined are: (i) abrasion resistance (ASTM D1044), (ii) hardness (ASTM D2240), and flexural strength (ASTM D790). During tensile testing, 5 identical standard dumb bell shape samples of dimensions: $165 \mathrm{~mm}$ of length $\mathrm{x} 19 \mathrm{~mm}$ of 
width $\times 3.3 \mathrm{~mm}$ of thickness were cut from each composite and used to determine the tensile properties the composite. Testing speed was set at $5 \mathrm{~mm} / \mathrm{min}$ and carried out at room temperature. Values for the tensile strength, elongation at break and tensile modulus were recorded and calculated automatically by the instrument's software. Flexural properties were determined using three point bending tests. The span length was set at about $50 \mathrm{~mm}$. Testing speed was set at $2 \mathrm{~mm} / \mathrm{min}$ and carried out at room temperature and specimen dimensions are $125 \mathrm{~mm} \times 12.5 \mathrm{~mm} \times$ $3.3 \mathrm{~mm}$. Hardness (Shore D) of the composite samples were tested using digital Durometer. For abrasion resistance of the samples, $4 \times 4$ inch flat specimens were subjected to abrasion by means of a Taber Abraser with a load of 500 grams on each CS-10F Calibrate Wheel for 100 cycles and operated in accordance with the code procedure. Haze measurements were made in accordance with code procedure before and after subjecting the specimens to abrasion by means of a PivotableSphere Hazemeter. From the required measurements, the light scattered as a result of abrasion being computed in accordance with the code procedure.

\section{Results and Discussions}

\subsection{Mechanical properties}

\subsubsection{Effect of Filler Content on Tensile Strength of composites}

Table 1 shows the effect of filler content on the tensile strength of PALP/HDPE composites. The tensile strength of the composites was observed to increase with increase in PALP (filler) content for all filler contents investigated. The tensile strength of the composites was found to increase by $6.49 \%$ at $2 \mathrm{wt} \%$ filler content (least filler content), and $30.39 \%$ at $10 \mathrm{wt} \%$ filler content (maximum filler content). The observed trend of increase in tensile strength of the composites with increase in filler content may be attributed to two main factors: the better dispersion of filler in the polymer, and filler-matrix interaction. The increase of tensile strength of HDPE composites with increase in filler content observed in this study was similar to the findings of other researchers. Sanjaya [14]; Onuegbu and Igwe [15], and Shao-Yun et al [16] reported increases in tensile strength with increases in filler content. It is important to note that for poorly bonded filler particles in the matrix, the stress transfer at the filler/polymer interface will be inefficient, thereby tending to discontinuity in the form of debonding because of non-adherence of filler particles to polymer. Thus, the filler particles cannot carry any load and the composite strength decreases with increasing filler content. However, for composites containing well-bonded filler particles, the addition of filler particles to the polymer will lead to an increase in strength, especially for filler particles with high surface areas.

Table 1. Effect of Filler Content of PALP on the Tensile Strength of HDPE Composites.

\begin{tabular}{|c|c|c|c|c|c|c|}
\hline Wt. \% of Filler & 0 & 2 & 4 & 6 & 8 & 10 \\
\hline Tensile Strength $(\mathrm{MPa})$ & 19.25 & 20.50 & 21.59 & 22.76 & 23.70 & 25.10 \\
\hline
\end{tabular}

\subsubsection{Effect of Filler Content on Tensile Modulus of Composites}

Modulus (stiffness) is another basic property of composites. The main aim of filler incorporation is usually to increase the stiffness of the resultant material. Table 2 shows the effect of filler content on the tensile modulus of PALP/HDPE composites. Like was observed on the effect of filler content on the tensile strength of PALP/HDPE composites, the tensile modulus of the composites was observed to increase with increase in PALP content for all the investigated filler contents. The tensile modulus of the composites was found to increase by $6.81 \%$ at $2 \mathrm{wt} \%$ filler content, and $25.39 \%$ at $10 \mathrm{wt} \%$ filler content for the composites. This increase in tensile modulus is to be expected when rigid fillers have been incorporated into softer polymer matrices since at high filler content, the composites will be able to withstand greater load [17]. Ardhyananta et al [18] who worked on polymer composites reported results similar to ours on the increase of tensile modulus of composites with increase in filler content. Natural lignocellulosic fillers have been 
found to have modulus that are higher than those of polyethylene, polypropylene, and some other polymer materials [19]. Because of this, the rigidity of their composites tends to increase on addition of these fillers [20]. Some authors also related the increase in composites' rigidity with the reduction of polymer chains mobility in the presence of fillers [21].

Table 2. Effect of Filler Content of PALP on the Tensile Modulus of HDPE Composites.

\begin{tabular}{|c|c|c|c|c|c|c|}
\hline Wt. \% of Filler & 0 & 2 & 4 & 6 & 8 & 10 \\
\hline Tensile Modulus (MPa) & 525.20 & 560.96 & 599.63 & 623.50 & 639.86 & 658.55 \\
\hline
\end{tabular}

\subsubsection{Effect of Filler Content on Elongation at Break of Composites}

Table 3 shows the effect of filler content on the elongation at break of PALP/HDPE composites. It can be seen that the elongation at break for all the PALP/HDPE composites decreases with increase in filler content for all filler contents investigated. The elongation at break of untreated PALP/HDPE composites was found to decrease by $2.40 \%$ at $2 \mathrm{wt} \%$ filler content, and $10.24 \%$ at $10 \mathrm{wt} \%$ filler content. Increasing filler content in HDPE matrix resulted in the stiffening and hardening of the composites. This reduced the matrix resilience and toughness, and led to the lowering of elongation at break [17]. The reduction in elongation at break with increasing filler content is an indication of the inability of the embedded filler to support the stress transferred from the filler to the matrix. The composites elongation at break therefore decreases as the fibre's stiffness increases. Jacob et al [17] in their studies reported that the addition of stiff fibre into a polymer matrix interrupted the polymer (HDPE) segments mobility and thus, making the polymer to become more brittle [22]. This, in turn, reduces the elongation at break of the composites.

Table 3. Effect of Filler Content of PALP on the Elongation at Break of HDPE Composites.

\begin{tabular}{|c|c|c|c|c|c|c|}
\hline Wt. \% of Filler & 0 & 2 & 4 & 6 & 8 & 10 \\
\hline Elongation at Break (\%) & 623.00 & 608.00 & 595.00 & 585.10 & 575.11 & 559.20 \\
\hline
\end{tabular}

\subsubsection{Effect of Filler Content on Abrasion Resistance of Composites}

Abrasion resistance is a property which allows a material to resist wear. It has been observed that an increase in tensile modulus of fillers brings about increases in abrasion resistance and hardness of composites [23]. This is because fibres are naturally stiffer than polymeric materials. Therefore, when a fibre is incorporated into a polymer matrix, it makes the composite to become stiffer and harder thereby, enhancing its abrasion resistance [24]. From Table 4, it can be observed that the abrasion resistance for PALP/HDPE composites increases with increases in filler content for all the filler contents investigated. The abrasion resistance of the composites was found to increase by $12.40 \%$ at $2 \mathrm{wt} \%$ filler content, and $17.92 \%$ at $10 \mathrm{wt} \%$ filler content. This study shows that the abrasion resistance of PALP/HDPE composites increases with increases in the tensile modulus of composites. Lee and Wang [25] in their studies on polymer composites had reported increases in the abrasion resistance of composites with increases in the tensile modulus.

Table 4. Effect of Filler Content of PALP on the Abrasion Resistance of HDPE Composites.

\begin{tabular}{|c|c|c|c|c|c|c|}
\hline Wt. \% of Filler & 0 & 2 & 4 & 6 & 8 & 10 \\
\hline Abrasion Resistance (\%) & 13.95 & 15.68 & 15.89 & 15.99 & 16.23 & 16.45 \\
\hline
\end{tabular}

\subsubsection{Effect of Filler Content on the Hardness of Composites}

A material is said to be hard when it is firm, stiff, and difficult to press down, break, or cut. Hardness is also a measure of how resistant solid matter is to various kinds of permanent shape change when a force is applied. The hardness of a material is dependent on ductility, elastic stiffness, plasticity, strain, strength, toughness, viscoelasticity, and viscosity. The effect of filler content on the hardness (Shore D) of PALP/HDPE composites are illustrated in Table 5. It is 
evident that the hardness of PALP/HDPE composites increased with increases in filler content for all the filler contents investigated. This observation is in agreement with the findings of Onuegbu and Igwe [15] whom reported that at a given filler particle size, the hardness of polypropylene composites increased with increases in the amount of filler incorporated into polypropylene. This was attributed to the stiffer filler increasing the hardness of HDPE. Therefore, the more the incorporation of filler (PALP), the greater will be the hardness of HDPE. From this study, the hardness of the injection and extrusion moulded untreated PALP/HDPE composites was increased by $14.03 \%$ at $2 \mathrm{wt} \%$ filler, and $23.47 \%$, at $10 \mathrm{wt} \%$ filler content. It is envisaged that the filler (PALP) being stiffer and more rigid than HDPE will make the resulting composites harder as more of it is incorporated into the HDPE [26].

Table 5. Effect of Filler Content of PALP on the Hardness of HDPE Composites.

\begin{tabular}{|c|c|c|c|c|c|c|}
\hline Wt. \% of Filler & 0 & 2 & 4 & 6 & 8 & 10 \\
\hline Shore D Hardness & 40.56 & 46.25 & 47.11 & 47.98 & 49.43 & 50.08 \\
\hline
\end{tabular}

\subsubsection{Effect of Filler Content on Flexural Strength of Composites}

The effect of filler content on the flexural strength of PALP/HDPE composites is shown in Table 6. As observed from the Table, the flexural strength of PALP/HDPE composites increased with increases in filler content for all the filler contents investigated. At $2 \mathrm{wt} \%$ filler content, the flexural strength increased by $5.26 \%$, while at $10 \mathrm{wt} \%$ filler content, the flexural strength increased by $28.95 \%$. The observed increases in flexural strength with increases in filler content is attributable to the better increased surface area of filler in the matrix and the fact that the filler which is known to have high crystalline content, is stronger and stiffer than the matrix and is, therefore expected to share the load applied in the matrix effectively with the crystalline fibrils in it [27].

Table 6. Effect of Filler Content of PALP on the Flexural Strength of HDPE Composites.

\begin{tabular}{|c|c|c|c|c|c|c|}
\hline Wt. \% of Filler & 0 & 2 & 4 & 6 & 8 & 10 \\
\hline Flexural Strength (MPa) & 19.00 & 20.00 & 21.21 & 22.30 & 23.00 & 24.50 \\
\hline
\end{tabular}

\section{Conclusions}

The present study has highlighted the utility of pineapple leaf powder (PALP) as a cheap, more readily available, and more environmentally friendly reinforcing filler in HDPE compounding as can be justified from the following observations: (i) The tensile strength, tensile modulus, flexural strength, abrasion resistance, and hardness of PALP/HDPE composites generally increased with increases in filler content for all the filler contents investigated, and (ii) The elongation at break (EB) of PALP/HDPE composites decreased with increases in filler content for all the filler contents investigated. The use of pineapple leaf powder (PALP) as filler in compounding polymers is also expected to help to minimize environmental pollution, reduce plastic wastes disposal and management problems by imparting some degree of biodegradability to the polymers. It is recommended that the use of pineapple leaf powder (PALP) as a filler should be extended to the processing of other polymers (plastics) so as to ascertain its likely wide acceptance or otherwise as a reinforcing filler for polymer industry. 


\section{References}

[1] T. Nishino, N. Arimoto, Current international research into cellulose nanofibres nanocomposites, Biomacromolecules. 8 (2007) 2712-2716.

[2] A.K. Mubarak, A.K.M. Idriss, Characterization of wood and wood-plastic composite, Polymer-Plastic Technology and Engineering. 38(4) (1999) 753-765.

[3] F. Corrales et al., Chemical modification of jute fibres, Journal of Hazardous Materials. 144 (2007) 730-735.

[4] E. Zini, M. Scandola, Green composites: an overview, Polymer Composites Journal. 32(12) (2011) 1905-1915.

[5] A.K. Mohanty, M. Misra, L.T, Drzal, Natural fibres, biopolymers and biocomposites, LLC, Boca Raton, FL, Taylor and Francis Group, USA, 2005, pp. 231-245.

[6] K.O. Niska, M. Sain, Wood polymer composites, Cambridge, England and Boca Raton, FL, Woodhead Publishing Ltd and CRC Press, USA, 2008, pp. 2341-2421.

[7] B.C. Bonse et al., Effect of Compatibilizer and bamboo fibre content on the mechanical properties of PP-g-MA compatibilized polypropylene/bamboo fibre composites, Proceedings of the Polymer Processing Society 26th Annual Meeting, 26, Banff, Canada, July 4-8, 2010, pp. 2120-2231.

[8] R. Malkapuram, V. Kumar, S.N. Yuvraj, Recent developments in natural fibre reinforced polypropylene composites, Journal of Reinforced Plastics and Composites. 28 (2008) 11691189.

[9] X. Ma, J. Yu, J.F. Kennedy, Studies on the properties of natural fibre-reinforced thermoplastic starch composites and carbohydrate polymers, Journal of Science and Technology. 62 (2005) 119-124.

[10] B.H. Lee, H.J. Kim, W.R. Yu, Fabrication of long and discontinuous natural fibre reinforced polypropylene - biocomposites and their mechanical properties, Fibres and Polymers, Polymer Science and Technology. 10 (2009) 283-298.

[11] H.D. Rozman et al., Polypropylene hybrid composites: a preliminary study on the use of glass and coconut fibre as reinforcements in polypropylene composites, Plastics Technology and Engineering. 38(5) (1999) 997-1011.

[12] M.C. Khoathane, O.C. Vorster, E.R. Sadiku, Hemp fibre-reinforced 1-pentene/polypropylene copolymer: The effect of fibre loading on the mechanical and thermal characteristics of the composites, Journal of Reinforced Plastics and Composites. 27 (2008) 1533-1543.

[13] I.Z. Bujang, M.K. Awang, A.E. Ismail, Study on dynamic characteristics of coconut fibre reinforced composites, Regional Conference on Engineering Mathematics, Mechanics, Manufacturing and Architecture. (2007) 185-202.

[14] K.B. Sanjaya, Study on mechanical behaviour of polymer based composites with and without wood dust filler, A Thesis Submitted In Partial Fulfillment of the Requirements for the Degree of Bachelor of Technology in Mechanical Engineering, Department of Mechanical Engineering National Institute of Technology Rourkela, India, 2010.

[15] G.C. Onuegbu, I.O. Igwe, The effects of filler contents and particle sizes on the mechanical and end-use properties of Snail shell powder filled Polypropylene, Materials Sciences and Application. 2 (2011) 811-817.

[16] S.F. Fu et al., Effects of particle size, particle/matrix interface adhesion and particle loading on mechanical properties of particulate-polymer composites, Composites Part B: Engineering. 39(6) (2008) 933-961. 
[17] M. Jacob, S. Thomas, K.T. Varughese, Mechanical properties of sisal oil palm hybrid fibre reinforced natural rubber composites, Composite Science and Technology. 64 (2004) 955965.

[18] H. Ardhyananta, H. Ismail, T. Takeichi, Effect of organoclay loading and ethylene glycol on mechanical, morphology and thermal properties of ethylene vinyl acetate/organoclay nanocomposite, Journal of Reinforced Plastics and Composites. 26 (2007) 789-796.

[19] I.O. Eze, I.C. Madufor, M.U. Obidiegwu, The effects of bamboo powder on some mechanical properties of recycled low density polyethylene (RLDPE) composites, Academic Research International. 4(1) (2013) 409-419.

[20] S.N. Das, T.K. Khastgir, D.K. Chakraborty, Effect of filler blend composition on the electrical and mechanical properties of conductive AVE composite, Project Euclidation. 8 (2002) 457-634.

[21] A.K. Rana et al., Short jute fibre reinforced polypropylene composites: effect of compatibilizer, Journal of Applied Polymer Science. 69(2) (1998) 329-338.

[22] M. Jamal et al., Tensile properties of wood/kenaf fibre polypropylene hybrid composites, Journal of Applied Polymer Science. 105 (2007) 3054-3059.

[23] A. Grozdanov et al., Rice hulls as an alternative reinforcement in polypropylene composites, Agronomy and Sustainable Development. 26 (2006) 251-255.

[24] B.V. Kokta, R.G. Raj, C. Daneault, Use of wood flour as filler in polypropylene: Studies on mechanical properties, Polymer Plastic Technology and Engineering. 28 (1989) 247-276.

[25] S.H. Lee, S. Wang, Properties of natural fibre reinforced polypropylene composites, Journal of Material Science. 37 (2006) 180-191.

[26] B. Wang et al., Effects of chemical treatments on mechanical and physical properties of flax fibre-reinforced rotationally molded composites, ASAE Annual Meeting. 2 (2007) 127-892.

[27] D. Chandramohan, K. Marimuthu, Tensile and hardness tests on natural fibre reinforced polymer composite material, International Journal of Advances in Engineering, Science and Technology. 6 (2011) 97-104. 